\title{
Seismic risk and hazard management at Kidd Mine
}

\author{
NV Disley Glencore Canada Corp., Canada
}

\begin{abstract}
Kidd Mine located in Timmins, Ontario is the deepest base metal mining operation in the world producing $2.3 \mathrm{~m}$ t of copper-zinc ore using open stope blast hole mining down to 9500 level or 2,900 $\mathrm{m}$ below surface. The mine has an extensive history of seismicity with monitoring systems in place since the mid 1980s. Currently a combination of microseismic and macro seismic systems are used to monitor the mine from the 800 level to the 9600 level. As mining proceeded to depth in Mine D below the 6800 level, managing the potential seismic hazard became increasingly critical as deeper mining zones came into production.
\end{abstract}

All data is manually processed in house and analysed using seismic analysis software tracking levels of seismicity within predefined sections of mining blocks or groups. Seismic hazard is estimated for individual stopes located within the groups to assess ground support requirements and potential post blast re-entry times using grid and group based hazard maps and b-values. Seismic source parameters such as apparent stress, energy index, apparent volume, static and dynamic stress drops, and stress drop ratio are monitored to detect potential instability in all mining blocks. Omori analysis is used post blast to track volumetric seismic response relative to the stope location for unusual trends that may suggest a more regional response or delayed energy release.

This paper will review the process of determining seismic risk for various areas of the mine as well as individual stopes. Seismic hazard management utilising flow chart based re-entry protocols, regional pillar failure source parameter trends, potential shear rupture planes at depth, and a case study will be discussed.

\section{Introduction}

The Kidd orebody is a steeply dipping massive sulphide deposit which extends from surface to below 3,000 $\mathrm{m}$ and has been continuously mined since 1964 with the bulk of current mining below the 6800 level in the final extension of operations called D Mine. The massive sulphide and copper stringer orezones are contained within a strongly schistose Rhyolite host rock, with stiff blocky Andesite in the mine footwall, and a stronger Greywacke contact to the south. There are several groups of fault systems that run through the mine including soft north dipping 'gouge' type faults and burst-prone south dipping quartz carbonate filled faults, all increasing in frequency with depth. Also, there a number of other structures at depth that were not detected in the Upper Mine, which differ in strike and dip from the traditional Kidd Mine geological structures.

Previous mining commenced with the open pit, moving underground with Number 1 Mine, Number 2, Phases 1 and 2 of Number 3 Mine, and finally D Mine, with planned mining to the 9500 level or over $2,900 \mathrm{~m}$ below surface. Open stope blast hole mining on $20 \mathrm{~m}$ wide primary and secondary panels, with cable bolted stope backs, and delayed paste filling is the current mining method. The onset of seismicity started during the mid 1980s in Number 1 Mine, generally below the 1600 level at depth of 490 m, and not limited to sills or pillars. At the time, a 64 channel source location seismic monitoring system was purchased and installed to cover mining in Number 1 and 2 Mines from the 1600 level to the 4600 level. To monitor mining in Number 3 Mine, a 32 channel source location system was added to extend coverage to the 6000 level. In 1993 the first full waveform digitizing macro or strong ground motion seismic system was installed, complete with low frequency geophones located distant from mining, to provide an estimate of Local Richter magnitudes for larger events. 
This system was basically a kit purchased through the International Association of Seismology and Physics of the Earth's Interior (IASPEI). The digitizing computer was located on surface with signals coming up Number 1 Mine shaft via the same copper cable that serviced the source location systems.

When it became obvious that the orebody extended to depth, and with increasing seismicity, it was decided in 1997 to purchase a full waveform microseismic system to replace the existing source location system in 3 Mine. A 64 channel Engineering Seismology Group Canada (ESG), HMSi microseismic system was purchased and installed, complete with triaxial accelerometers utilising the original uniaxial accelerometers from the source location system, to monitor from the 4700 level to the 6800 level. This provided accurate locations and triaxial source parameter information for all seismic events. At this time, the macro or strong ground motion system was upgraded to an ESG digital drum recorder to provide Local Nuttli magnitudes for large events roughly calibrated to the Geological Survey of Canada. A second 64 channel system was purchased in 2005 and gradually expanded to the 8600 level as D Mine was being developed. As further extension of seismic coverage was required for Block 4 of $D$ Mine down to the 9600 level, 24 bit Paladin Viper six channel seismic stations were added to complete the array.

For a number of factors, the foremost of which was the withdrawal of hardware support for the outdated HMSi systems, it was decided to replace the two HMSi arrays with network based ESG Paladin Viper seismic stations. In 2012, the macro or strong ground motion system was upgraded, with the addition of two ESG network based Paladin 4 stations with $4.5 \mathrm{~Hz}$ geophones. These were located deeper in the mine, and closer to some critical mine infrastructure that is sensitive to high vibration levels from seismic events or stope blasting. In 2013, the fibre optic seismic Ethernet network was extended to the original Strong Ground Motion stations on the 800 and 2400 levels, which were subsequently replaced with Paladin $4 \mathrm{~s}$ and $4.5 \mathrm{~Hz}$ geophones allowing the stations to function as an array.

Currently the Kidd Mine microseismic systems effectively covers from the 6000 level to the 9600 level, with a series of thirteen six channel Paladin Viper seismic stations, in two separate arrays connected to a $1 \mathrm{~GB}$ ethernet network. Time synchronisation within the arrays is achieved using a one pulse per second timing signal over a dedicated fibre from a timing source on the 9400 and 6800 levels. The sensor arrays consist of a combination of triaxial and uniaxial accelerometers, plus $4.5 \mathrm{~Hz}$ and $15 \mathrm{~Hz}$ geophones, with all seismic stations sampling at $20 \mathrm{KHz}$. Data is streamed over the network to a $10 \mathrm{~TB}$ central acquisition server located on surface, storing both automated event triggers and a continuous ten day trace, any section of which can be accessed and saved as unique event files as required. Acquired data is then automatically moved across to, and analysed on, a seismic processing work station in the same office.

The strong ground motion system consists of $4 \times 3$ channel Paladin 4 seismic stations plus one Paladin Viper all with $4.5 \mathrm{~Hz}$ geophones. These are located in mined out areas, with the farthest station on the 800 level, some $2,700 \mathrm{~m}$ above the lowest production level. Fibre optic cables were run to these areas in order to get these upgraded stations on the seismic network and have them also streaming data to an acquisition server on surface. In the absence of a dedicated timing fibre, time synchronisation between the Paladin 4 stations is achieved using the IEEE 1588 precision timing protocol (PTP) in conjunction with switches between each site that are compatible with PTP. The lone Paladin Viper in the array is synchronised using the network time protocol (NTP) and takes slightly longer to synchronise when rebooted. Event triggers and continuous trace data is stored on a separate strong ground motion server with events being transferred to the main seismic processing computer for analysis and correlation with the microseismic systems. The local Nuttli magnitudes from the strong ground motion system are calibrated to the Geological Survey of Canada.

See Figure 1 for a schematic of the complete Kidd Mine seismic network. 


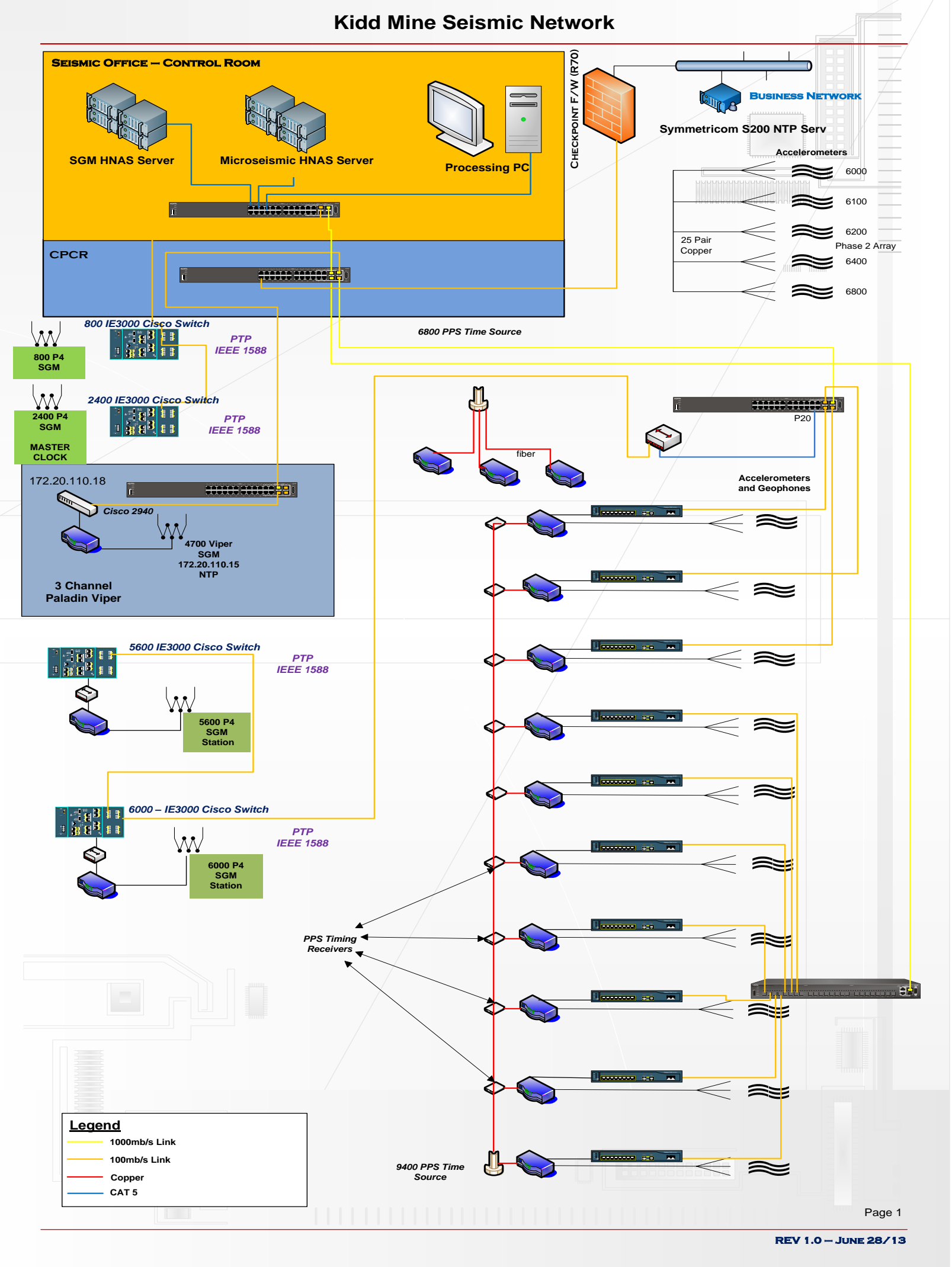

Figure 1 Kidd Mine seismic network 


\section{Methodology}

Waveform data from all systems is manually reprocessed on site, with noise events deleted and blasting tagged, to ensure the best possible data quality in both Upper and Lower Mine seismic databases. Data is then imported into the Mine Seismicity Risk Analysis Program (mXrap) (Australian Centre for Geoemchanics 2014). Within $m X r a p$, imported events are automatically sorted into seismic clusters or groups, which have been given meaningful names according to the various areas of the mine, and are displayed in the cluster tracking monitor (CTM). For ease of use the group naming convention matches the corresponding mining blocks from Phase 2 of Number 3 Mine to Block 4 of D Mine, the sill levels as the vertical boundaries, with each block further subdivided into 'North Abutment', 'South Abutment' and so on. The CTM will display levels of activity, as well as the number of 'significant' and 'large' events, over three variable time spans, so any variation in the level of activity for any group as compared to the background frequency is highlighted. A 'significant' event will have a microseismic triaxial magnitude of greater than -1.0, while a 'large' event is greater than 0 as tagged in $\mathrm{mXrap}$. The microseismic triaxial magnitude is the ESG peak particle velocity 'Tmag' without any uniaxial sensor information and equals Local Nuttli magnitude by adding 1.5.

Prior to the onset of mining, the seismic risk is estimated for planned future stopes and assigned a risk from moderate to very high by reviewing the seismic history for the group in which the planned mining is located (Figure 2).

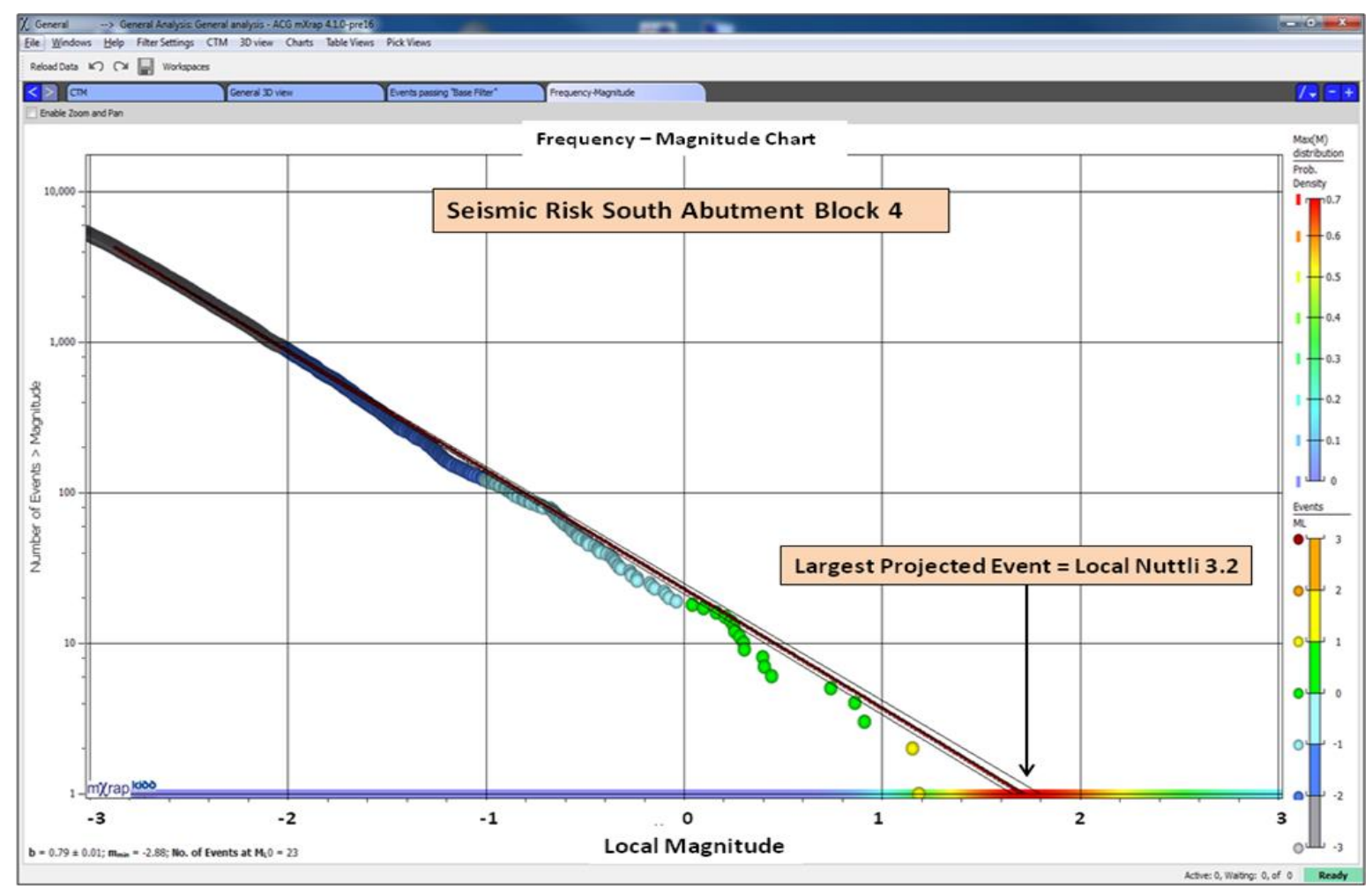

Figure 2 Frequency-magnitude chart for the south abutment of Block 4 - below 2,700 m

The largest estimated event magnitude is projected from all recorded events in the group and expressed as Local Magnitude in the horizontal axis, and in the example in Figure 2 by adding 1.5 the estimated Local Nuttli magnitude would be 3.2. Other methods for estimating the potential seismic risk for a given area of the mine are grid-based, (Wesseloo et al. 2014), and Cluster/Group risk assessments. The 'Grid-Based' analysis superimposes an event grid matrix of potential maximum magnitudes for regions of the mine relative to nearby development to focus on where the largest events could potentially occur. The Cluster/Group risk assessment colour codes the mine infrastructure with what the highest peak particle velocity these areas were exposed to based on the history of that particular group. Figures $\mathbf{3}$ and $\mathbf{4}$ are the seismic hazard maps for Block 4 starting at the 8800 level some 2,700 m below surface with one set of the major fault systems displayed. 


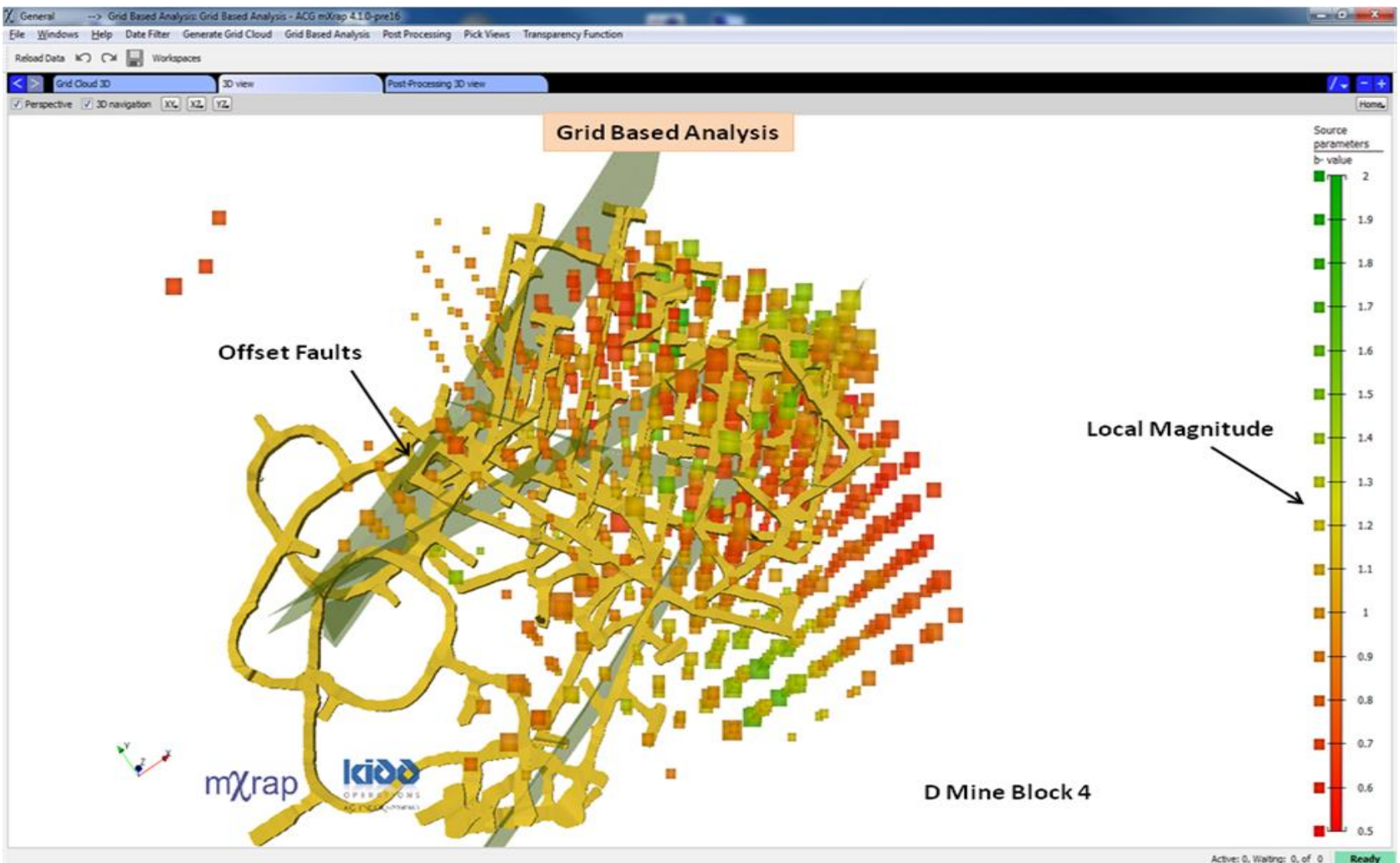

Figure 3 Grid-based risk analysis for Block 4

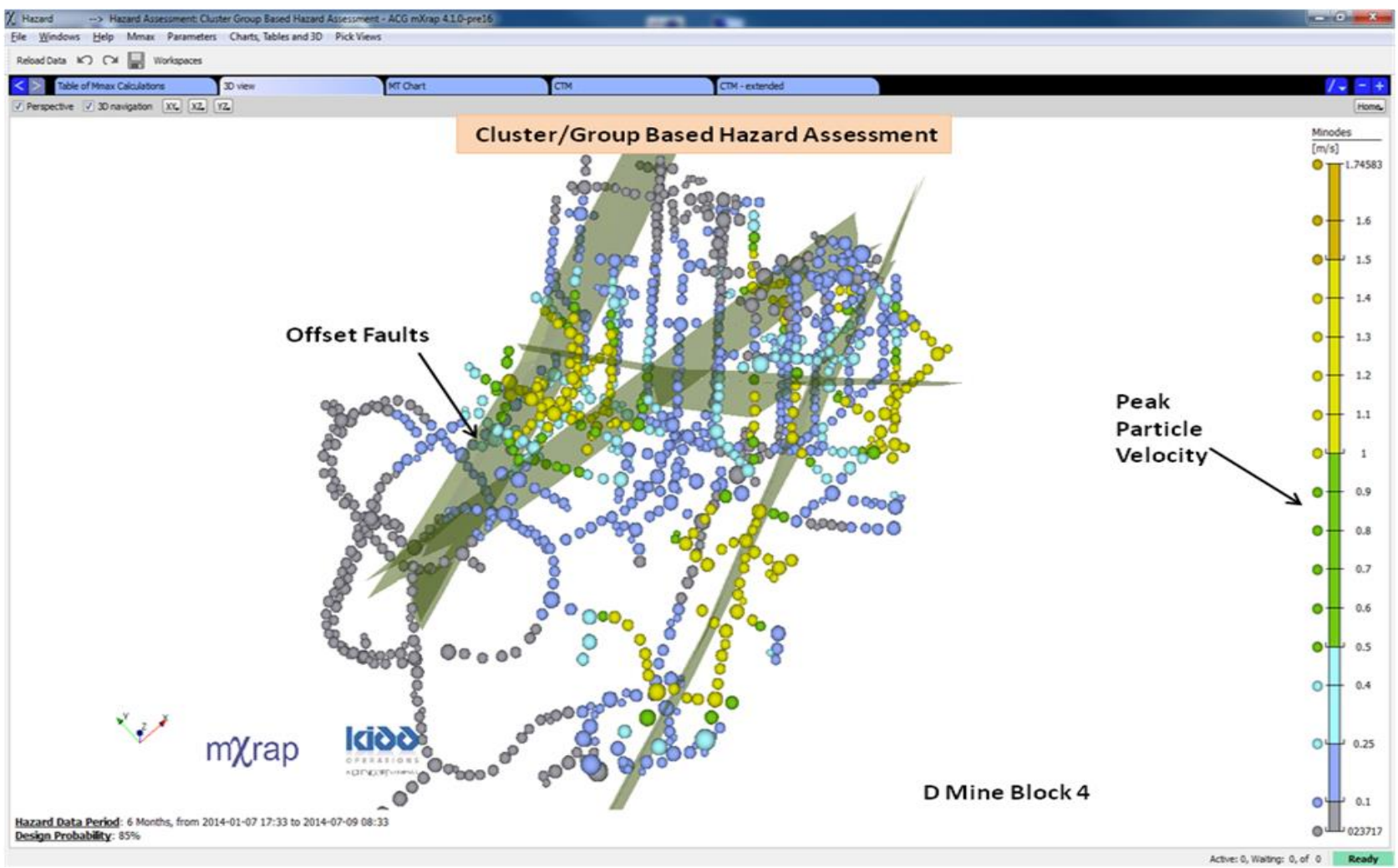

\section{Figure 4 Cluster/group risk analysis for Block 4}

Based on the seismic history of the South Abutment of Block 4 the images in Figures 2, 3, and 4 give an estimate as to what the potential largest event might be, from what area of the group it may originate, and what the potential maximum ground motion nearby infrastructure may be subjected to. When planning 
new development for this area, burst rated support systems with enhanced intersection support would be required to match the potential seismic risk. With the onset of stope blasting high levels of seismicity can be anticipated, with extended access restrictions involving multiple production levels, until such a time as the levels of activity returns to background, with the presence of active fault systems a major factor.

Following stope blasting operations or large seismic events, a number of source parameters are tracked within $\mathrm{mXrap}$ to identify unstable conditions, and determine appropriate re-entry times including:

- Event Rate.

- Apparent Stress - High Energy/Small moment = High apparent stress.

- Instability Analysis/Energy Index/Cumulative Apparent Volume (CAV) - comparison between empirical energy release and source size.

- Static/Dynamic Stress Drops - estimation of the stress change at the source.

- Stress Drop Ratio (Vasak 1999) - ratio between dynamic and static stress drops indicating the complexity of the source mechanism, with a low ratio suggesting simple fault slip.

- Omori Analysis - event locations and source parameter trends relative to the blast or large event location over time.

The definitions of the above parameters are expressed in the most simplistic terms and generally involve energy release, displacement, and estimated stress changes within specific volumes of rock. The general methodology used to authorise re-entry into restricted areas following blasting or large events using these source parameters is expressed in the flow chart in Figure 5.

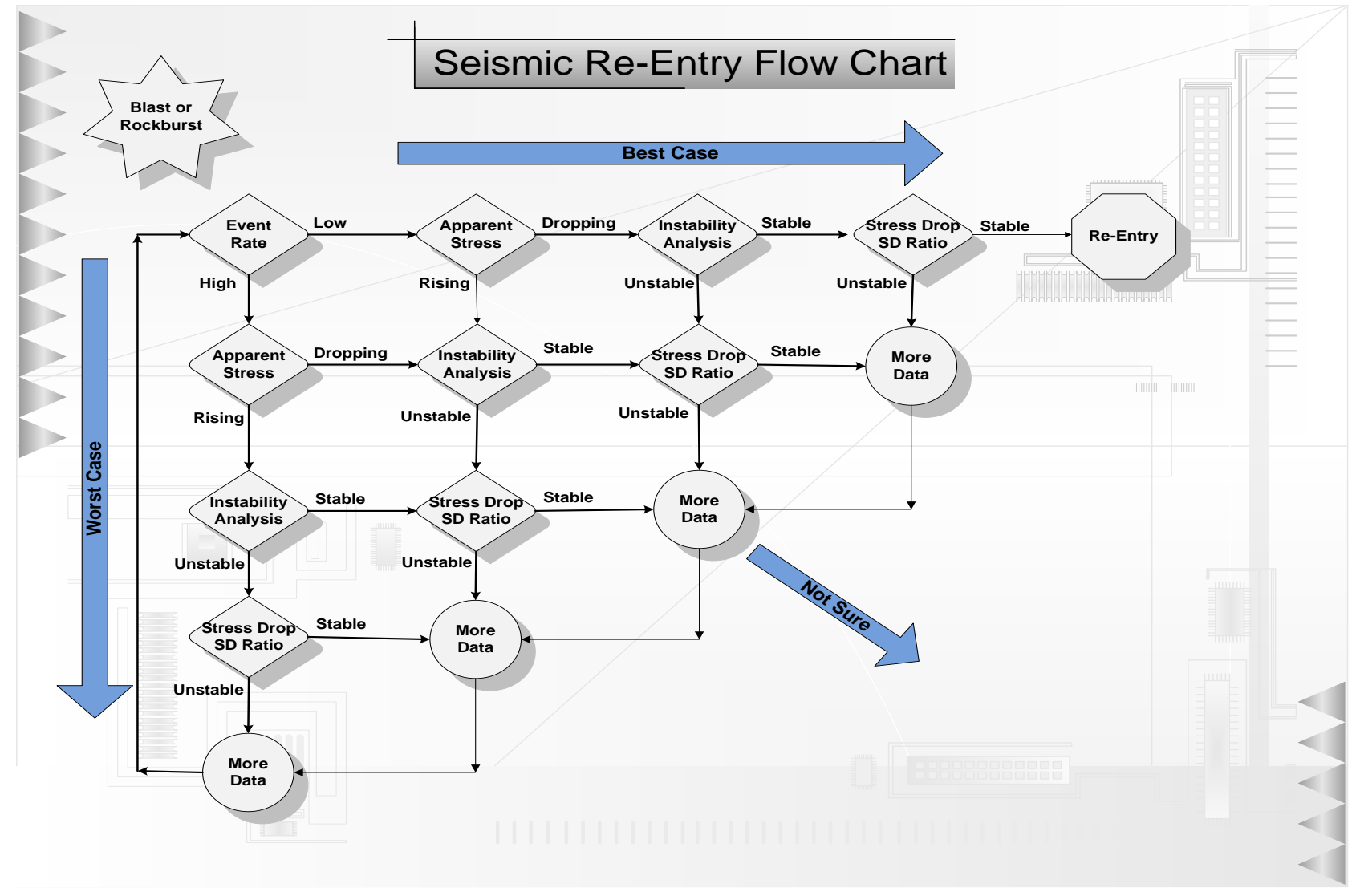

Figure 5 Seismic source parameter trend flow chart

While the best case and worst case scenarios are obvious, 'More Data' does not necessarily mean seismic data only. Additional data points in the re-entry decision making process are often made based on local 
ground support, the number of open stopes, proximity to major faults, and the size and scope of the geometry change in the case of stope blasts or magnitude for large events. In most cases even though some of the source parameters have not returned to background levels re-entry is possible with modified and extended restrictions isolating areas of highest seismic risk as in the hazard maps in Figures $\mathbf{3}$ and $\mathbf{4}$.

Typically rock mass readjustment with swarms of high apparent stress events in the immediate vicinity of the stope, occurs until such time as the nature of the events change, emitting less energy, with more displacement. At this point, changing source mechanism trends may signal an unclamping of nearby local structures as the ground yields around the freshly created opening, potentially increasing the fault slip hazard. Ideally, all source parameter trend lines will 'flatten out' or return to background levels suggesting some equilibrium has been reached and re-entry is possible.

In addition to the logic in Figure 5, an Omori analysis is useful in spatially and temporally plotting the incoming events in relation to the blast or large seismic event location. Events that start to occur at increasing distances from the initial event or blast location may signal a wider ranging readjustment is underway, requiring additional access restrictions to be put in place. In Figure 6, an example of a delayed seismic reaction following a small blast is presented, with high apparent stress events initially occurring very near the new opening, then followed six hours later by events up to $120 \mathrm{~m}$ away on a potential seismic shear plane.

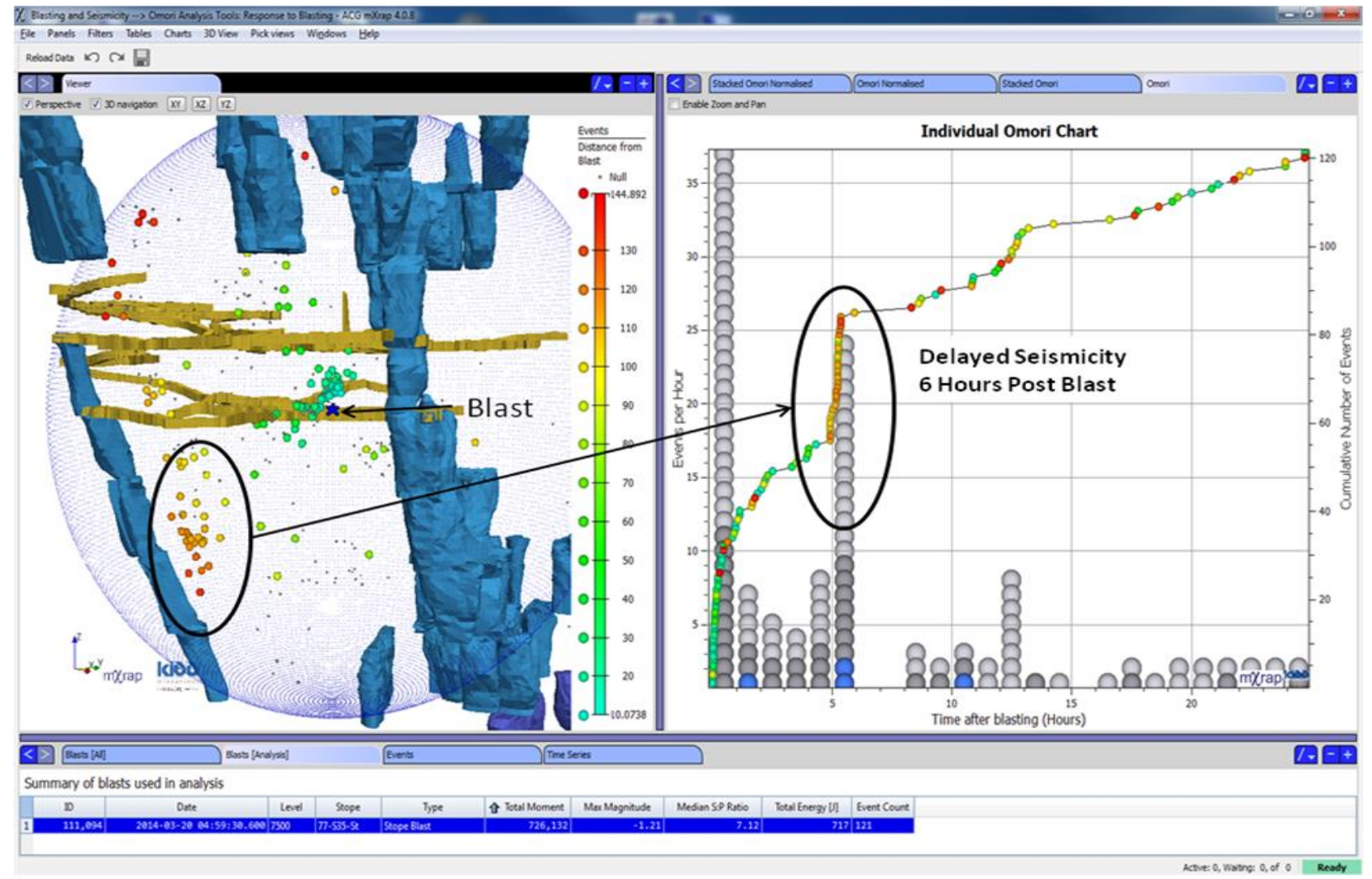

Figure 6 Omori analysis $150 \mathrm{~m}$ influence radius, coloured distance scale, and post blast histogram

\section{Data}

Areas of the Kidd Mine with the highest historic seismic hazard are the South Abutments of the individual mining zones, especially when simultaneous stoping was taking place in both the main ore and Greywacke zones. The high grade Greywacke massive sulphide satellite orebody generally follows the strike and dip of the main or zone through Phase 2, Blocks 1, 2, and 3 until it dissipates in Block 4. The presence of this zone creates a regional pillar within the stiff and blocky Andesite footwall rock further complicated by several 
south dipping burst-prone faults and an Andesite/Rhyolite contact continuous through each mining block. The East facing total mine view in Figure 7 illustrates the location in the south abutment of the waste pillar relative to the main orezone, with mining in Phase 2 being the most advanced. This area in Phase 2 and Block 1 is the source of the largest and most damaging rockbursts in the Kidd Mine seismic record, two of which with magnitudes of Nuttli 3.8 that created a shear rupture in the Block 1 waste pillar referred to as the 'Seismic Break'.

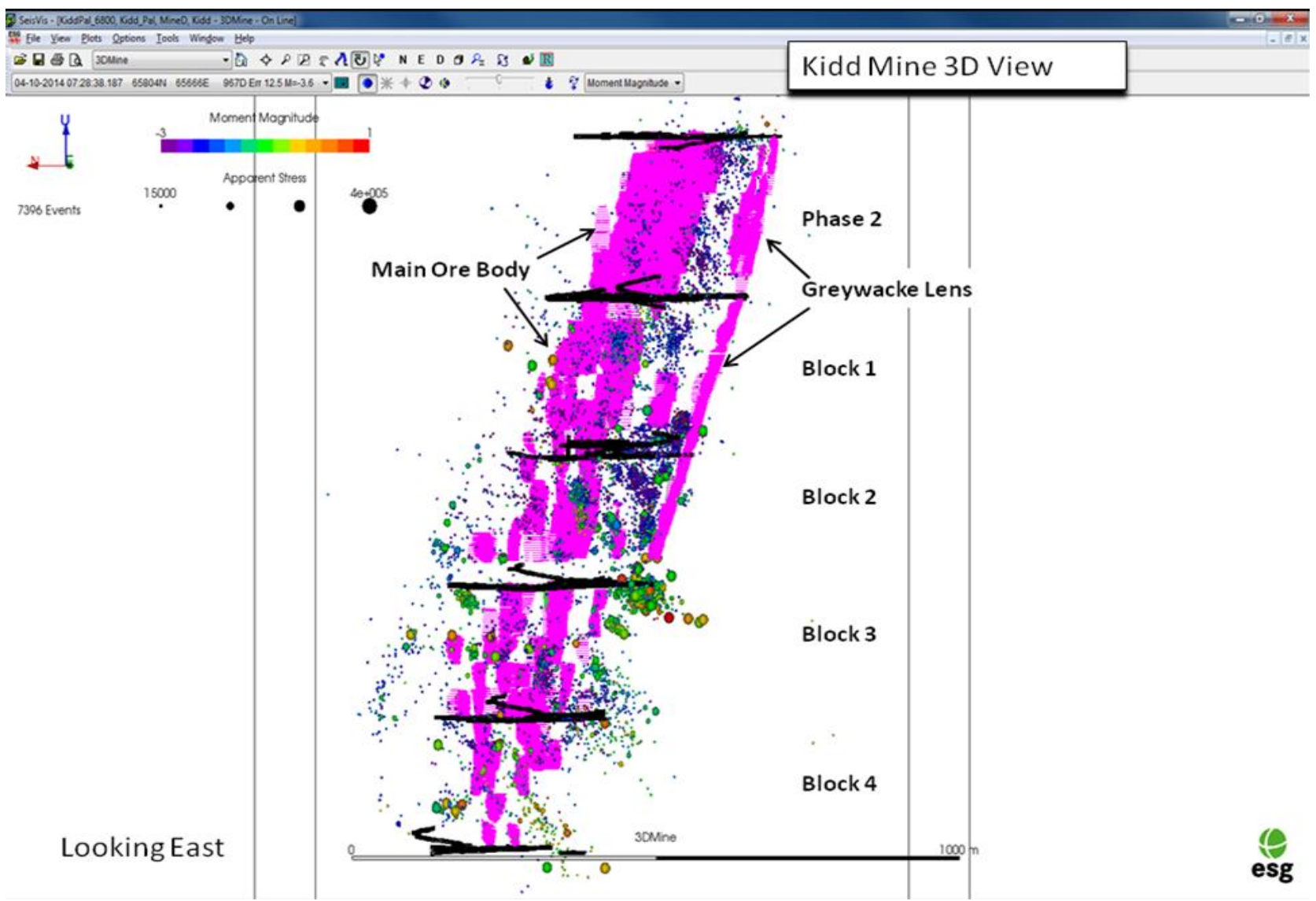
Figure 7 Mine section view showing main orebody, Greywacke zone, and waste pillar
with sill levels

Extensive modelling calibrated by the historic seismic response has indicated that the extraction of the Greywacke zone in the Southern abutment of the mine footwall has the potential to increase the short term energy release increasing the potential for major seismic events. Mining plans for the Greywacke zones in Blocks 1, 2, and 3 were deferred until late in the mine life when the main orebody has been substantially extracted. A strategy was implemented to gradually reduce the driving forces by allowing more gradual deformation of the main zone footwall by mining destress stopes moving south and west into the pillar so it would fail in a more controlled manner. There was evidence that this approach would be successful because of the seismic behaviour of the pillar in Phase 2 after a key stope was mined in mid 2009. Mining of the 64-GW2-St triggered a period of very high levels of seismicity accelerating a steep decline in the Apparent Stress, Stress Drops, and Energy Index but with an increase in the apparent volume, suggesting that the pillar was storing less and less strain energy but with increasing displacement per event. As the asperities and rock bridges failed allowing joints to slip and blocks to move the stress drop ratio declined towards a more pure shearing source mechanism which matched the ES/EP ratio trend closely.

Also, an unexpected pattern emerged in the seismicity, indicating that there were failure planes developing at angles across the pillar during this period that do not match the orientation of any of the known faults or contacts in the area (see Figure 8). The changing seismic source parameters were reinforced during underground observations with an increasing trend towards relaxation of the rock mass, water dripping 
through joint sets, blocks loosening, and deformation near the areas near the seismic failure planes. In Figure 9 the dramatic changes in the static stress drops and stress drop ratio is obvious with a strong correlation to the ES/EP ratio which is calculated independently from any other seismic source parameters. The patterns of seismicity and failure curves look somewhat similar to crushing a rock cylinder in a hydraulic press.

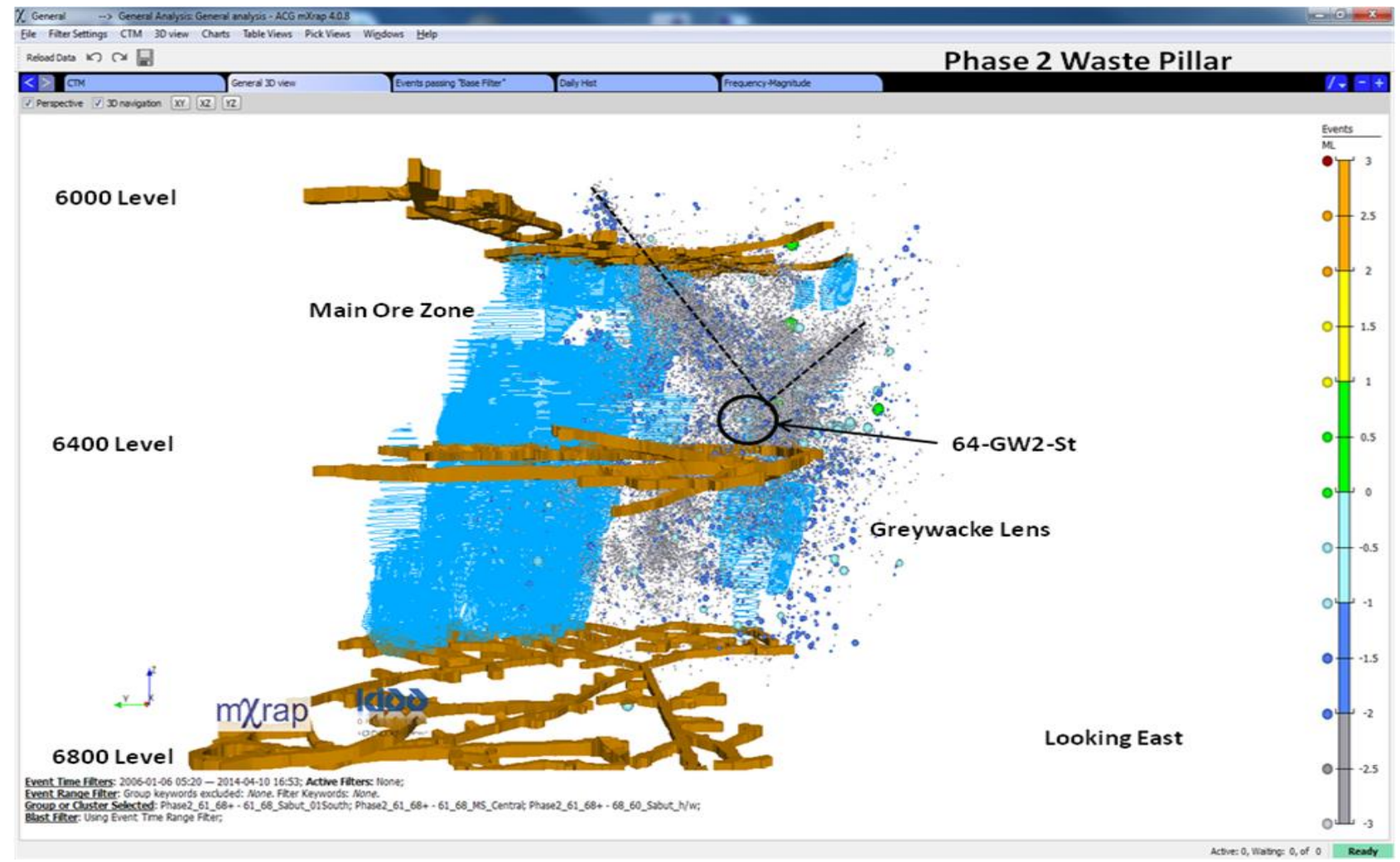

Figure 8 Phase 2 pillar showing seismic trends after 64-GW2-St

After September 2011 and the implementation of the revised mining sequence concentrating on the main orezone, several smaller stopes in the south abutments have been mined. Although data is over a shorter time period than in Phase 2, there is evidence to suggest that mining the strategically located destress stopes in Blocks 1, 2 and 3 of D Mine are having the desired effect of gradually advancing the deformation in a controlled fashion failing the pillar in shear. The source parameters from the area of the highest seismic hazard in Block 1 are showing similar trends to what was observed in Phase 2, especially since January 2013. There has been a marked increase in the Apparent Volume, decreasing Stress Drops, and changing Stress Drop Ratio suggesting a change in source mechanisms. The source mechanism data trend since January of 2014 show more slip and less fresh fracturing which corresponds to the mining of three destress stopes in the south abutments of Blocks 1 and 2 during the first quarter of 2014 (see Figure 10).

Some of the seismicity during this period, which has contributed to the changing source mechanisms, locates away from the freshly blasted stopes on a feature parallel to the seismic break called SB2. Seismic data and underground observations suggest that a number of parallel structures to the seismic break or SB1 have started to form as far down as Block 3, referred to as 3 and 4 Trends. These features have been identified underground as deformation zones with abundant fresh fracturing observed by the mine structural geologist that do not correspond to any previously mapped structure or contact. The image in Figure 11 shows the orientation of the seismic break or SB1 with all historical seismicity within $40 \mathrm{~m}$ of SB1 before and after the major events in 2009 and 2011. The down dip view illustrates the difference between the family of mapped south dipping faults which were always the most seismically active prior to 2009, and the more recently formed shear rupture. The revised mining sequence has allowed this feature to move and deform and release strain energy in a controlled fashion however there is seismic and observational 
evidence as previously discussed that several parallel ruptures could be created under the right circumstances.

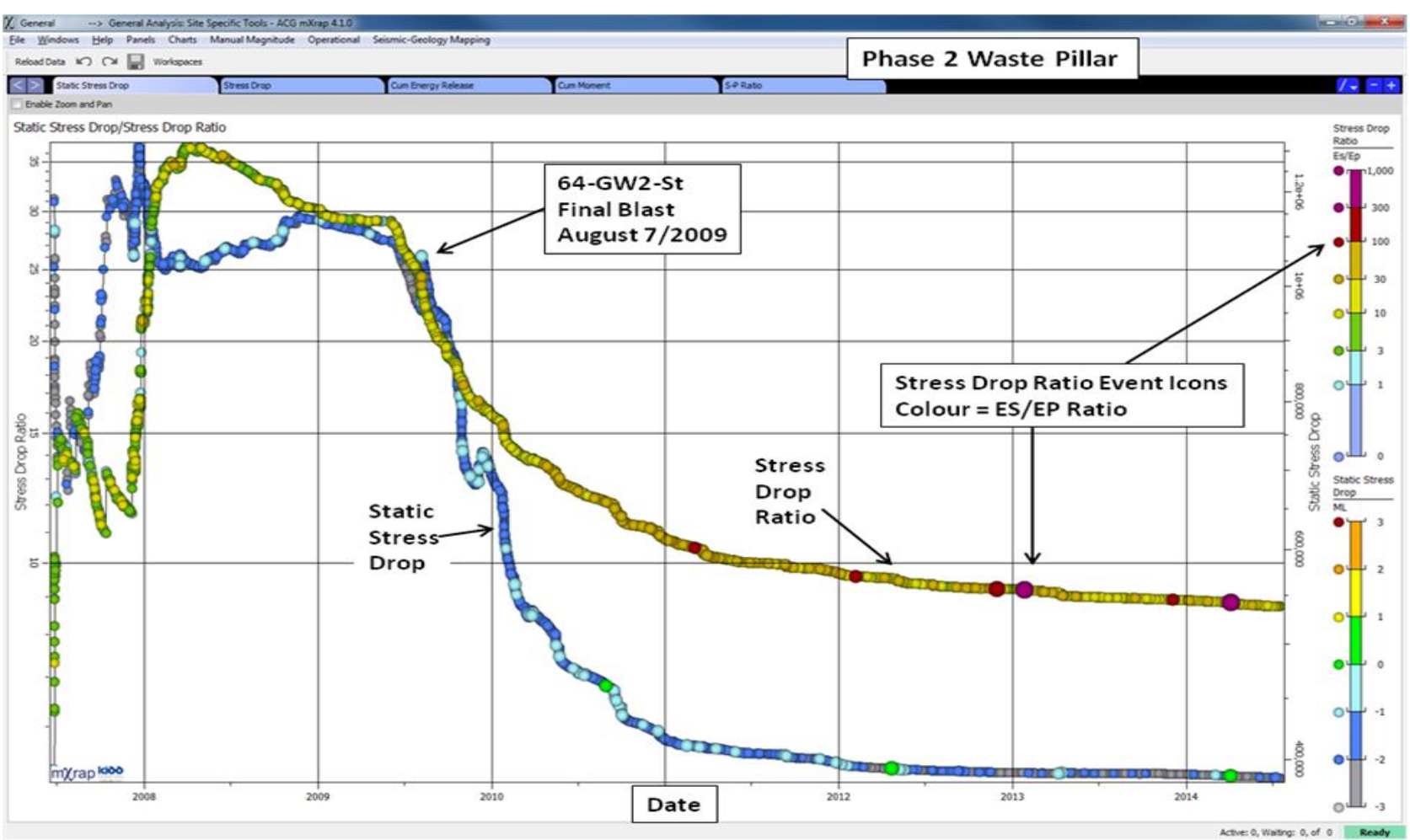

Figure 9 Phase 2 south abutment pillar Stress Drop/Stress Drop Ratio after 64-GW2-St

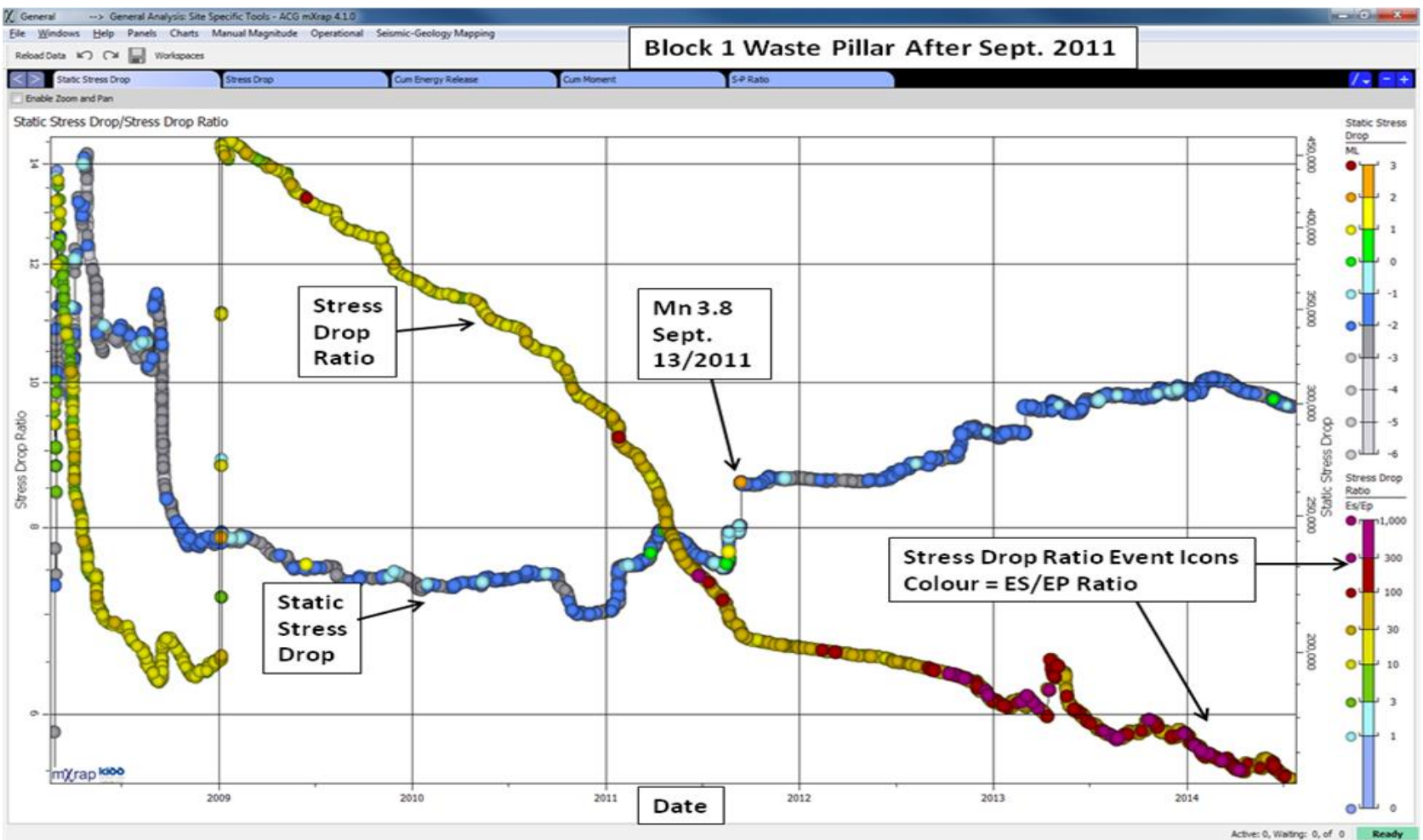

Figure 10 Block 1 pillar Stress Drop/Stress Drop Ratio after September 2011

There have also been several planar clusters of seismicity in the abutments of the Lower Mine that again do not match the assumptions that seismicity will conveniently line up in some predictable fashion along 
mapped structures. The presence of these increases the seismic risk for the area of the mine in which they occur as the events are more robust than the seismicity in the vicinity of the stopes.

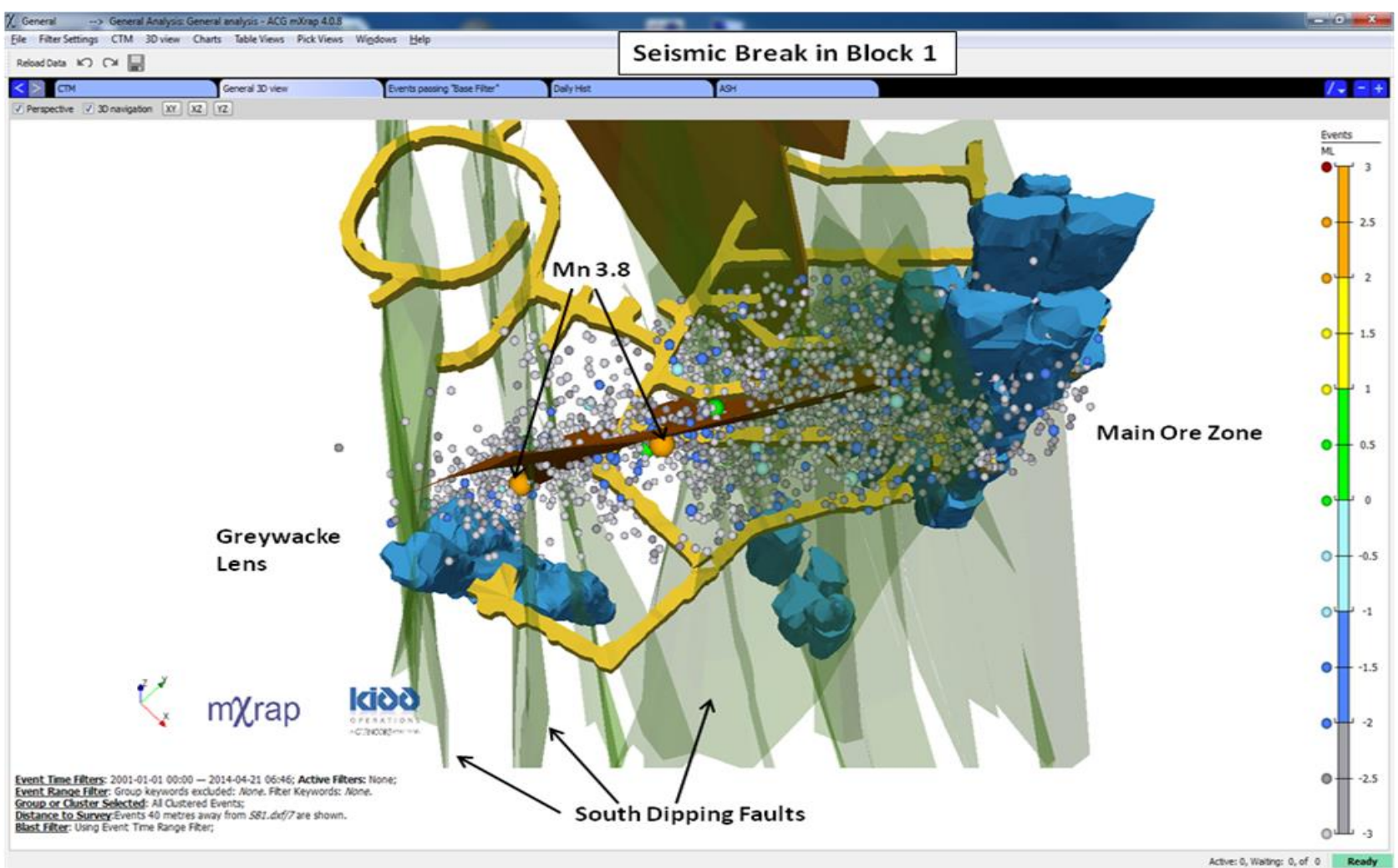

Figure 11 Looking down dip along the seismic break with 7000 level and south dipping faults

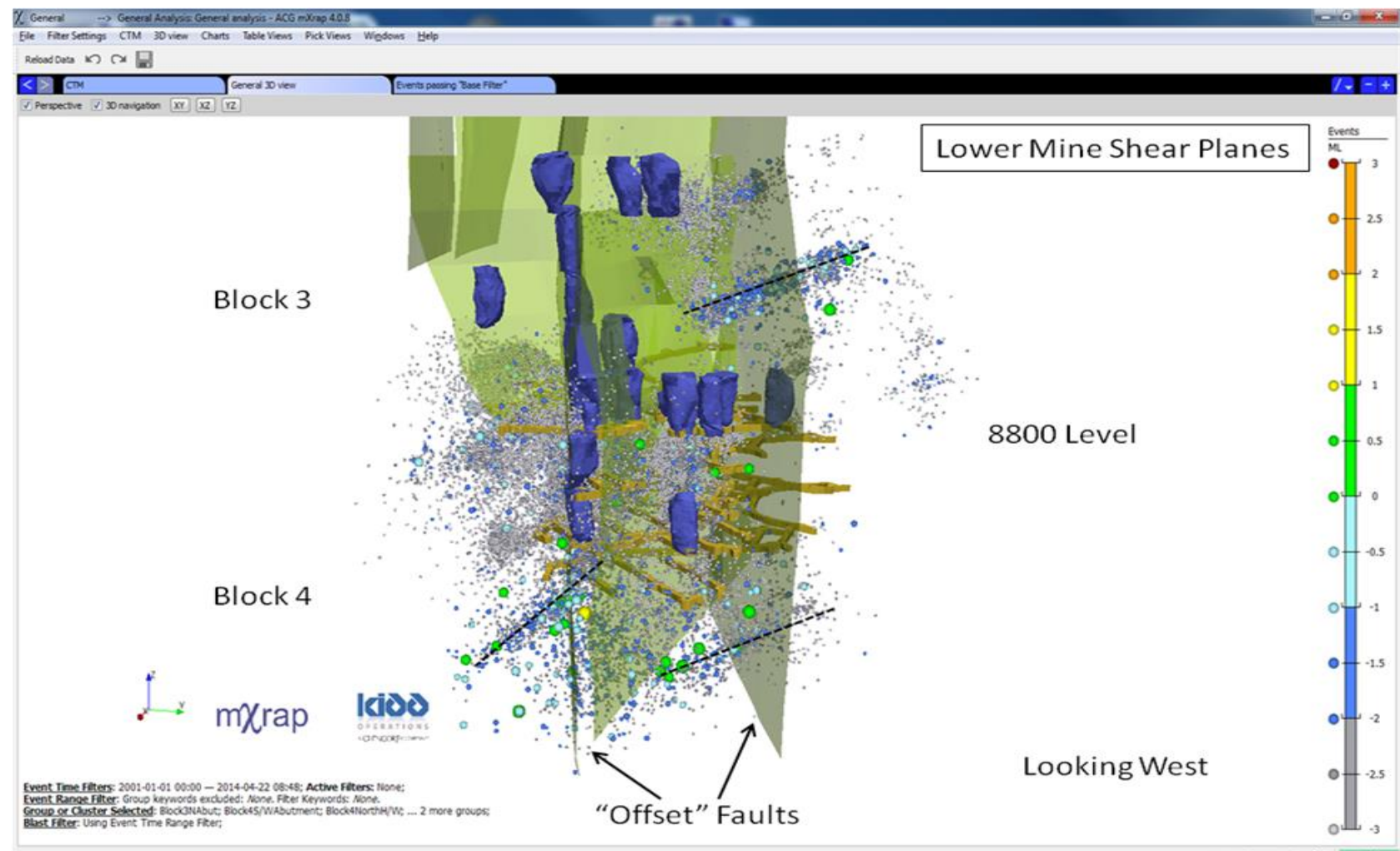

Figure 12 Potential shear planes in the Lower Mine 
The view in Figure 12 is from the hanging wall west along the strike of the offset faults illustrating that the seismic planes generally do not line up with the fault systems. In the case of the group in the north abutment of Block 3 the seismicity lines up with a flat lying lens of Andesite within the much softer Rhyolite in the copper orezone. In the South Abutment of Block 4 there are three rock types with a fold nose of Andesite that extends through the Rhyolite towards the Greywacke contact with the offset fault just to the north. Source parameter trends suggest complex failure mechanisms with much more shearing over the last two years for both zones as mining progresses. This behaviour differs in the Lower Mine abutments from the waste pillars in Phase 2 and Block 1 in that there is a gradual increase in Apparent Stress, Energy Index, and Stress Drops over time as stresses are shed into the abutments with little change in the Apparent Volume. In the case of Block 4 with the presence of a pronounced Andesite fold nose there is more potential for large events with projected displacement on the Offset Fault or shearing off of the Andesite nose.

Subsequently, seismic risk is managed by installing yielding, burst rated ground support in these areas an example of which was following the final blast in the 94-903-St. Located in the South Abutment of Block 4 the final in 94-903-St triggered a period of seismicity that included a Local Nuttli 2.4 strong ground motion event. Post blast seismicity located in the immediate area of the stope as well as scattered throughout the lower abutment of Block 4. Following an extended closure and subsequent site inspection by Ground Control, a re-assessment of the excavation vulnerability potential or EVP was required (Heal et al. 2006). It was decided that enhanced ground support was required in the stope access and 01 South drives prior to the resumption of mucking. In order to optimise the location and efficiency of this process the rehab plan basically mirrored the areas of highest seismic risk as shown in red in the group and cluster hazard assessment in Figure 13.

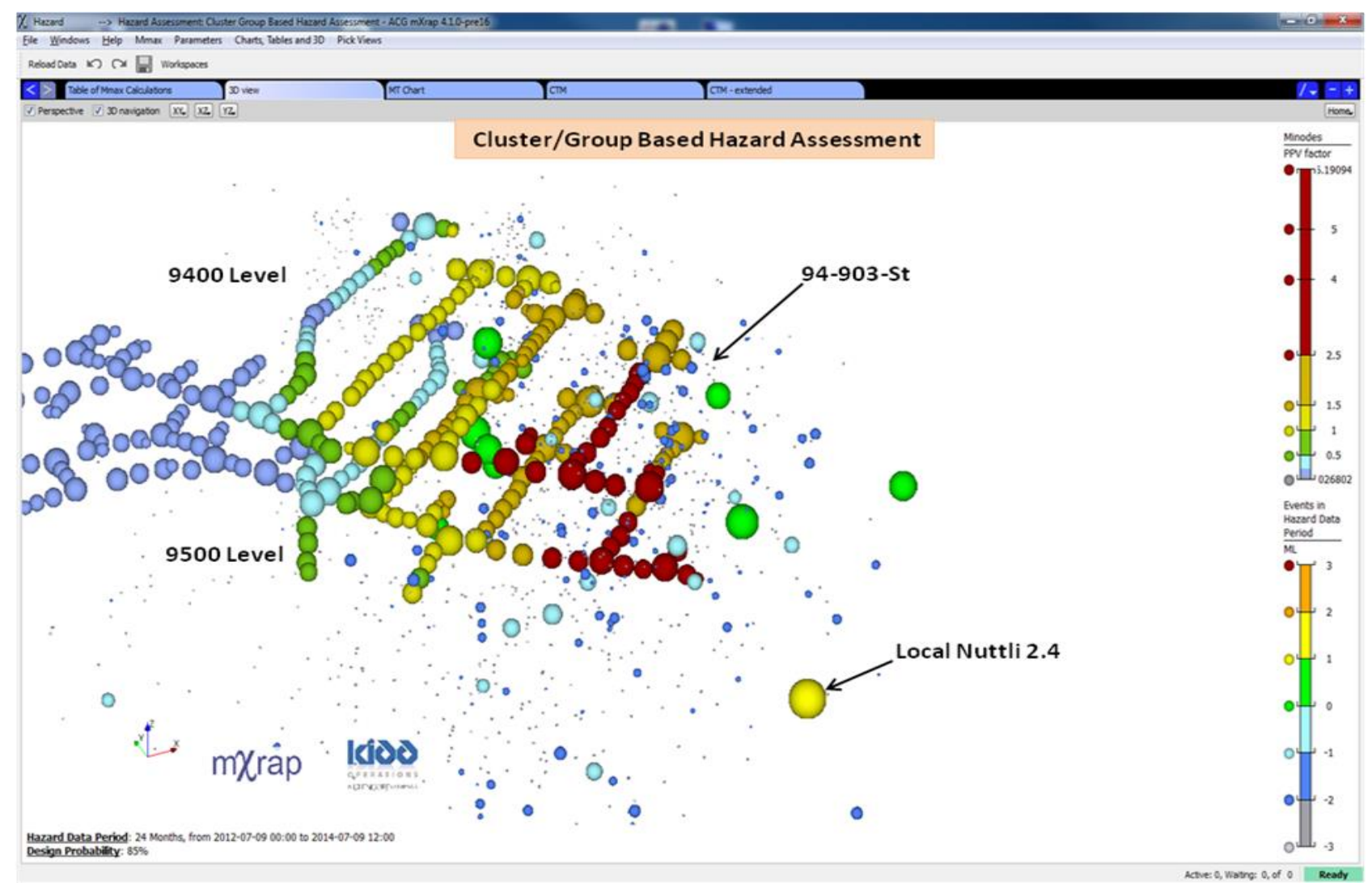

\section{Figure 13 Group-based hazard assessment for 9400 and 9500 levels following 94- 903-St}

There are several examples of local changes in the geometry of the mine in one area having a dramatic wide ranging effect over significant distances. On 3 August 2010 there was a large final blast in the 
69-826-St that was located in the South Abutment on the sill between Phase 2 and Block 1 with the overcut on the 6800 level. During the period following the blast, until 7 August there were over 1,400 seismic events fourteen of which triggered the mines' strong ground motion system with local Nuttli magnitudes ranging from 0.5-2.6. Of particular note the majority of the strongest events occurred in the opposite abutment of the mine, two mining blocks above the stope. There was a major regional adjustment on the south dipping faults in the north abutment from the 6800 level up to the 4400 level from 3-7 August with one of these structures less than $10 \mathrm{~m}$ from the footwall of the 69-826-St. The largest event in the data set located $460 \mathrm{~m}$ away from the stope with some as much as $900 \mathrm{~m}$ away during the period.

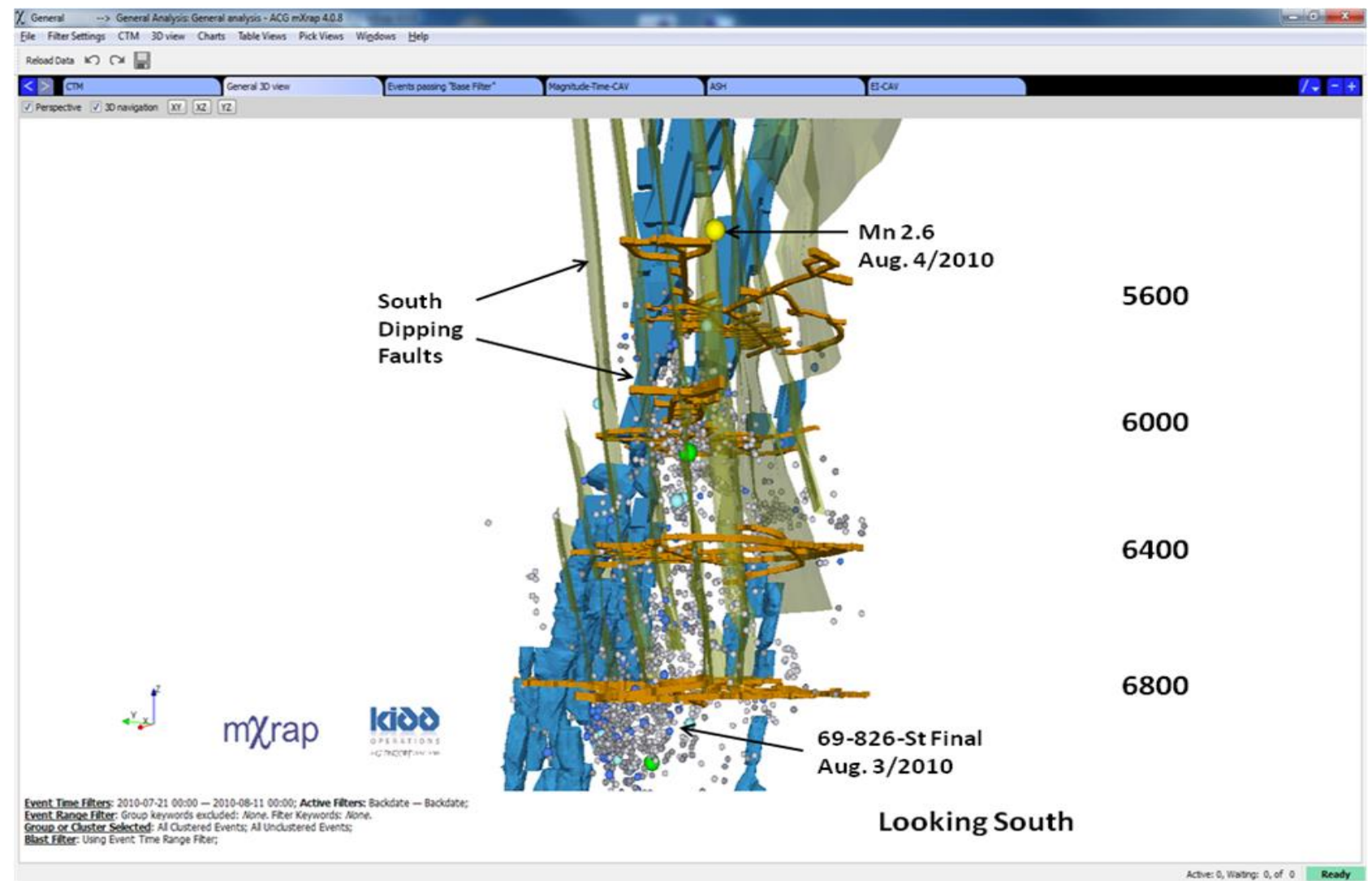

\section{Figure 14 Post blast seismicity along south dipping fault system}

As shown in Figure 14 there is a cluster of post blast seismicity in the immediate vicinity of the stope within the first 24 hours then a delayed reaction in the North Abutment; the largest event 40 hours post blast near the 5600 level \#4 Shaft station. The Omori analysis shows sporadic seismicity locating at increasing distances from the stope 24 hours after the blast up to the Mn 2.6 at hour 40 which triggers a major jump in activity in the north abutment above the 6000 level with some damage requiring repair at several locations.

The back analysis of the Energy Index/CAV instability chart as shown in Figure $\mathbf{1 5}$ is different from the typical post blast re-entry seismic hazard assessment in that all events within all groups and clusters during this period were used, instead of just the area around a single stope. The circled section of the graph is the 40 hour period between the blast and the Nuttli 2.6. The initial response from the blasting all originates from the south abutment of Block 1 which continued to be sporadically active between hour 24 and the Mn 2.6 at hour 40. The first event above the 6000 level at hour 40 was the Mn 2.6 so there were no precursory events to suggest that there was going to be a large event in this area however the sporadic wide spread seismicity and climbing Energy Index/CAV trend suggested that an unusual condition existed and that structures were regionally affected. There were at least seven strong ground motion events in the North Abutment of Phase 1 and 2 following the Mn 2.6 a with a large drop in Energy Index and jump in 
cumulative apparent volume indicating a potentially unstable condition resulting in additional access restrictions.

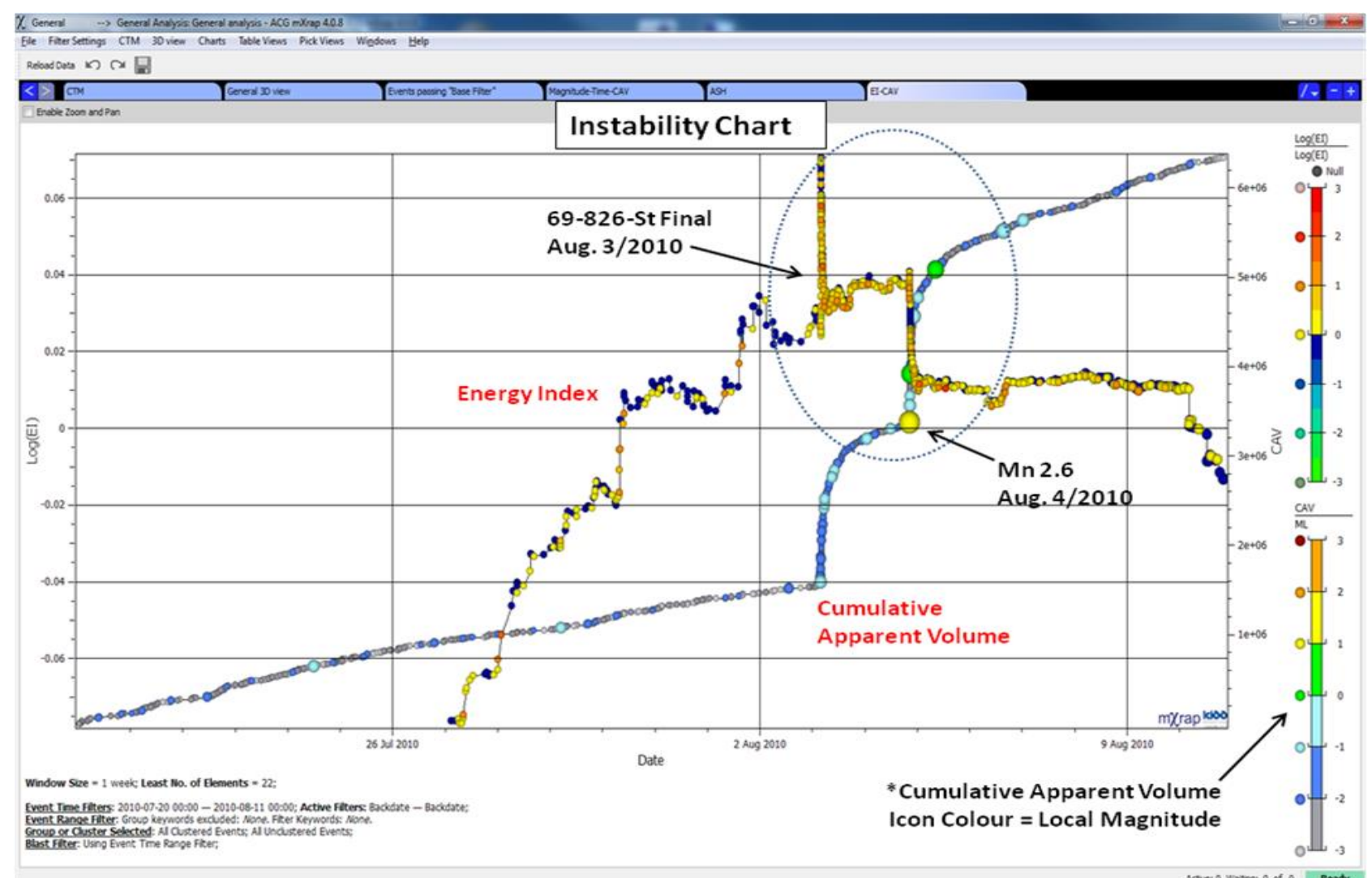

Figure 15 Energy index/CAV instability graph for \#3 Mine August 2010

\section{$4 \quad$ Results}

1. Using the seismic hazard/risk methodology described has helped optimise the selection of effective ground support systems for various areas of the mine.

2. Data-based seismic hazard and risk management in conjunction with the implementation of dedicated gas check/re-entry crews have contributed greatly to a more efficient and safe resumption of mining activity after blasting operations or large events.

3. Adopting a data-based strategy to gradually modulate regional deformation and ultimately fail regional waste pillars in shear has had encouraging results so far.

4. Other sections of the mine with unusual seismic trends and the potential for shear ruptures have been identified as areas of higher seismic risk, where dynamic support has proactively been installed.

\section{$5 \quad$ Conclusions}

1. Static stress drop and stress drop ratio trends have been valuable in indentifying failure in regional pillars.

2. There is a strong correlation between the Stress Drop Ratio and ES/EP ratio as an indicator of source mechanism trends.

3. Energy Index/Cumulative Apparent Volume trends in conjunction with post blast or large event Omori analysis have been useful indentifying wider range instabilities. 
4. Apparent Stress averages are useful in tracking local rock mass readjustments following blasting operations.

\section{Acknowledgement}

The authors thank the following for assistance in the preparation of this paper.

- Kidd Mine Management.

- Dave Counter - Senior Ground Control Engineer.

- Kidd Mine Ground Control - Dave Black, Ben Ollila, Jeremy Gulliver.

- Greg Cooper - Structural Geologist.

\section{References}

Australian Centre for Geomechanics 2014, mXrap, Australian Centre for Geomechanics, Perth, http://www.mxrap.com

Heal, D, Potvin, Y \& Hudyma, M 2006, 'Evaluating rockburst damage potential in underground mining', in DP Yale (ed.), Proceedings of the 41st U.S. Symposium on Rock Mechanics (Golden Rocks 2006): 50 Years of Rock Mechanics - Landmarks and Future Challenges, vol. 2, American Rock Mechanics Association, Alexandria, pp. 1221-1232.

Vasak, P 1999, Evaluation of Spatial and Temporal Trends at Kidd Creek Mine, internal report to Kidd Mine Ground Control, Timmins.

Wesseloo, J, Woodward, K \& Pereira, J 2014, 'Grid-based analysis of seismic data', Proceedings of the 6th South African Rock Engineering Symposium: SARES 2014, South African Institute of Mining and Metallurgy, Johannesburg, pp. 125-138. 
